\title{
Concaves influence on the milling process of cereal seeds in hammer mills
}

\author{
Anişoara Păun ${ }^{1, *}$, Gheorghe Stroescu ${ }^{1}$, Dumitru Milea ${ }^{1}$, Mihai Olan and Mariana Epure ${ }^{1}$ \\ ${ }^{1}$ National Institute of Research - Development for Machines and Installations designed to \\ Agriculture and Food Industry - INMA, Bucharest 013813, Romania
}

\begin{abstract}
Obtaining quality fodder that meets the requirements of fodder receipts makes necessary the use of components that have to respect certain dimensions. The milled products must respect the granulation imposed by the receipt because they are very well assimilated by animals and the homogenization process is also very good. The milling process is a complex one, influenced by a number of factors that depend on the technical and constructive solution of the milling chamber and on the physical and mechanical properties of the processed raw material (seeds). In the hammer mills with open chambers and sieve surface up to 180 degrees, the presence of concaves (grooved plates) within the milling chamber is a must because it will lead to the acceleration of the seed milling process and implicitly to increase the productivity and reduce electricity consumption. The paper follows the theoretical and experimental presentation of an open chamber mill that is provided with these grooved plates.
\end{abstract}

\section{Introduction}

The production of concentrated fodder for livestock sector is an important concern both at global and national levels.

Fodder use in animal feed, in its natural state, does not meet all the requirements of the animal body and therefore it must be processed before consumption according to a particular technological scheme [1]. The milling of concentrated fodder, as a component of feed preparation technological processes, is one of the basic operations. Hammer mills improvement has been the focus of many researchers, but in most of the published works there are only partial approaches to constructive and functional parameters that influence the operation regime.

The working process of the mill must be regarded as a stochastic process described by pseudo-static methods $[2,3,4,5]$. In this case, the established operation regime of the mill is a continuous, incidental, stationary process. Following the milling process, a multitude of small particles are formed, although milling can be characterized as a process of producing new surfaces of material particles. The size of the entire mass of the powdery material as a static mass is evaluated by the comprised content of classes (fractions), of certain dimensions, namely, by granulometric composition or granulation. Almost the entire

*Corresponding author: ani_paun@yahoo.com 
crushing and milling of inorganic materials involves a reduction from a one-dimensional distribution to a smaller distribution.

For this reason, many crushing theories are based on the dimensional connection from one distribution to another.

The milling process, in the case of hammer mills, is influenced by the following factors: technological, mechanical, constructive, functional [6].

The main mechanical factors influencing the milling process in hammer mills are: hammers impact on fodder particles, loss of deformation energy during shock, hammers peripheral speed, the movement speed of the fodder layer in the milling chamber, the fan effect produced by the hammer rotor, hammer rotor's moment of inertia.

The constructive factors that influence the milling process are: the size of the milling chamber, the constructive shape of the hammers, the size of the distance between hammers and sieve, the constructive shape of the grooves, the method of feeding the machine, the way of grain milling discharge. 8, 9]:

Seeds milling in hammer mills can be considered as being made up of three phases [7,

1- shredding of fodder particles due to collision with the hammers of the rotating rotor when entering the milling chamber;

2- shredding of particles in non-uniform movement resulting from the first collision and projected by hammers on the grooved plates and also by the edges of the sieve holes, which border the milling chamber;

3- shredding of fodder particles as a result of mutual collisions in the milling chamber.

\section{Theoretical research}

The open chamber hammer mill, MC-3, Figure 1, is a mill where fodder is tangentially fed by free flow through the entire milling chamber length $[2,3,6]$. Fodder feeding is made through an opening at the peripheral side; at the entrance to the milling chamber grain seeds are subject to strong hammer blows.

Due to these blows the grain seeds are shred, and the resulting particles are projected by the grooved plates (counter knives), and there the second shredding occurs. From these plates, the resulting particles rebound and reach the hammer area again, after which the phenomena repeat.

The shredding phenomenon also continues in the sieve area due to the shocks and friction between the fodder particles and the edges of the sieve holes. The sieve is more like a system of grain milling separation (removal) $[7,8,9]$.

Particles smaller than the sieve holes, under the action of the air flow created by a fan (mounted outside the mill) and centrifugal forces, pass through the sieve and reach the discharge and transport duct that connects to the separation and collection systems.

In these mills, fodder milling is made especially due to collisions between the hammers and the fodder particles, respectively the concaves.

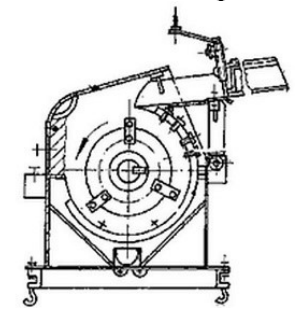

Fig. 1.Hammer mill with open chamber, MC-3 
The concave is the fixed part in the milling chamber participating in the seed shredding operation and which may be of different shapes: cylindrical, semi-cylindrical or cylindrical with groove, teeth or hole active surface $[6,7]$.

There are situations where the concave is missing, its role being taken over by the hole sieve. The use of groove or teeth concave leads to the best results in terms of shredding process quality.

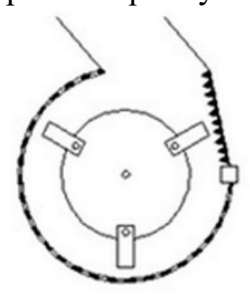

a

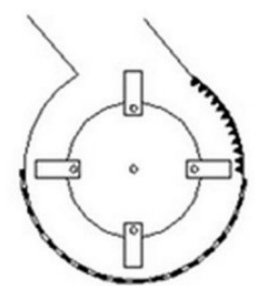

b

Fig. 2. Constructive variants of sieves and concaves used in the open chamber hammer mill a - the sieve with the coverage angle of the milling chamber of $255^{\circ}, b$-the sieve with the coverage angle of the milling chamber of $180^{\circ}$ with another type of counter knife

We consider that the particle moves in the milling chamber in the area between the hammer rotor and the concave and strikes the concaving point $\mathrm{A}$ at the speed $v_{p}$ (particle speed impacted by the hammer) at angle $\alpha$ having the normal at the point of contact, Figure 3.

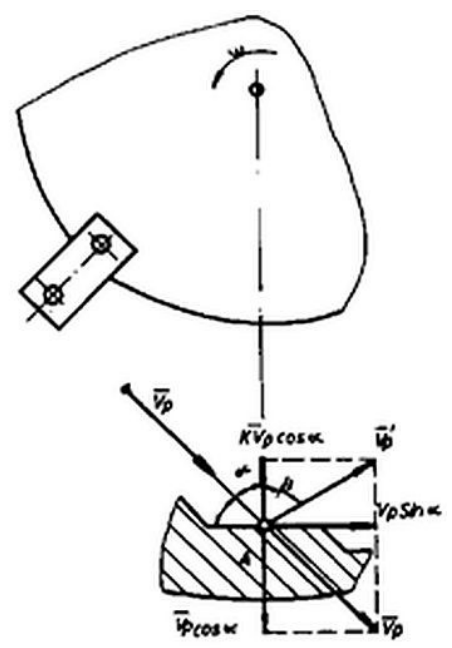

Fig. 3. Scheme of speeds at particle collision with the concave in shredding process [2]

The angle between the normal in the point of contact and the direction of the particle velocity after the collision is noted $\beta$

The concave is fixed, it results that its speed before and after the collision is null.

The case to be studied can be assimilated with:

- the oblique collision, with no friction, of two spheres, in which a sphere is represented by the concave's wall;

- the oblique collision, with friction, of two spheres.

As frictions are neglected, the tangential components of speeds will not change. The component $v_{p} \sin \alpha$ following the direction of the concave's wall does not change; the other component $v_{p} \cos \alpha$ changes its sense and as value it becomes $\mathrm{kv}_{\mathrm{p}} \cos \alpha$, since $v_{p n}=k v_{p}$. 
After collision, the particle speed will be $v_{p}^{\prime}$ and will have the following expression:

$$
v_{p}^{\prime}=\sqrt{v_{p}^{2} \sin ^{2} \alpha+k^{2} v_{p}^{2} \cos ^{2} \alpha}=v_{p} \sqrt{\sin ^{2} \alpha+k^{2} \cos ^{2} \alpha} \leq v_{p},(\mathrm{~m} / \mathrm{s})
$$

Angle $\beta$ can be expressed in terms of particle speed before collision as follows:

$$
\operatorname{tg} \beta=\frac{v_{p} \sin \alpha}{k v_{p} \cos \alpha}=\frac{1}{k} \operatorname{tg} \alpha(2)
$$

As in the studied case the coefficient of restitution is $k \leq 1$, from relation (2) it results that $\beta \geq \alpha$.

By analyzing relations (1) and (2), it is found that if there is collision of a sphere (fodder particle) with a fixed wall, the particle speed after collision $v_{p}^{\prime}$ decreases and the speed vector deviates from the normal.

After the collision with the concave, the particle rebounds. In order for the particle, after hitting the concave, to return to the hammer action area, it is necessary that the normal component of the speed after the collision is maximum. This situation occurs for:

$$
\begin{aligned}
& \alpha=\{\beta=0 \\
& v_{p}^{\prime}\left\{v_{n \text { max }}^{\prime}=-k v_{p}(3)\right. \\
& k=\ell
\end{aligned}
$$

In concaves construction, the grooves are designed so that the incidence angle $i$ has the maximum value $\mathrm{i}=\frac{\pi}{2}$, Figure 4 .

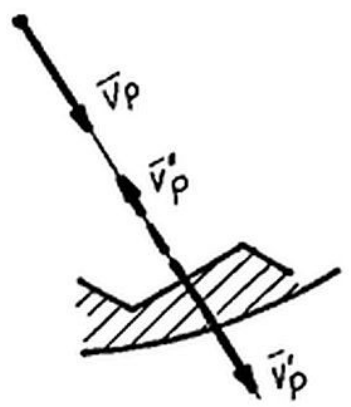

Fig. 4. Situation when the incidence angle has the maximum value [2]

The intensity of the blows (shocks) between the fodder particles and the grooved surface is also influenced by the radial distance between the circle described by the top end of hammers and the grooved surface, which must be as small as possible.

In the case of oblique collision, due to the friction forces, the relative speed and the rebounded particle movement direction correspond only partially to the laws of elastic collision, Figure $5 \mathrm{a}$ and $\mathrm{b}[10]$.

In Figure $5 \mathrm{a}$, it is noted the case when the granule rebounds at an angle smaller than the angle of collision with the hammer.

In the case of breaking, the granules rebound as a dispersion cone with an angle bigger than the collision one (Figure 5b).

After the collision with hammers, the granules obtained hit the inner surfaces of the mill, undergoing a new shredding process. 


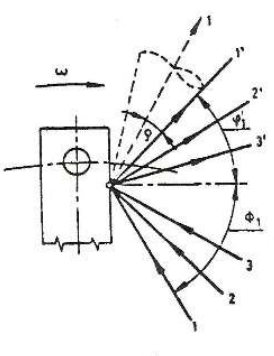

$\varphi_{1,2, \ldots \mathrm{n}}<\Phi_{\mathrm{i}, 2 \ldots \mathrm{n}}$

a

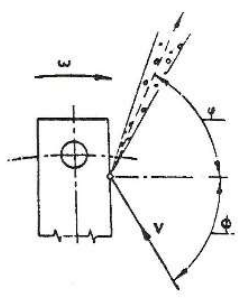

$\varphi>\Phi$

b

Fig. 5. Oblique collision-rebounding of granules [10]

a) without granule breaking; b) with granule breaking

\section{Experimental research}

The main objective of the experimental research was to verify the influence of the concaves on the grinding modulus and the power consumption in the process of milling the maize and barley seeds. Experimental research was carried out at the National Institute of Research - Development for Machines and Installations Designed to Agriculture and Food Industry - INMA Bucharest.

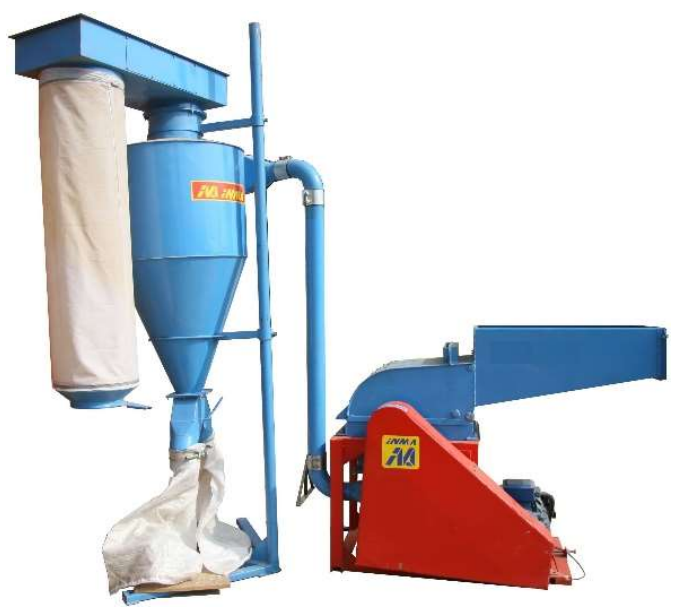

Fig. 6. Open chamber mill MC 22

The mill in Figure 6 consists of the following main sub-assemblies: frame, lower housing, upper housing, collecting chamber, assembled rotor, fan, tensioner, $22 \mathrm{~kW}$ electric motor.

The parameters that influence the performance of hammer mills are:

$\mathrm{Q}$ - feed rate of the mill, $\mathrm{kg} / \mathrm{h} ; \mathrm{v}_{\mathrm{c}}$ - peripheral speed of the hammers, $\mathrm{m} / \mathrm{s} ; \mathrm{D}$ - diameter of the hammer rotor, $\mathrm{m} ; \mathrm{v}_{\mathrm{ds}}-$ movement speed of the seed bed in the milling chamber, $\mathrm{m} / \mathrm{s} ; \mathrm{z}$ - no. of hammers; $b$ - hammer width, mm; e - distance between hammers top end and sieve, $\mathrm{mm}$; $\mathrm{d}$ - diameter of sieve holes in the milling chamber, $\mathrm{mm} ; \beta$-milling chamber's angle of coverage, degrees; 1 -hammer length, $\mathrm{mm} ; \mathrm{q}_{\mathrm{a}}$ - the amount of air required to remove the material from the milling chamber, $\mathrm{m}^{3} / \mathrm{min} ; \mathrm{A}$-total area of the sieve holes, $\mathrm{mm}^{2}$;

$\mathrm{M}$-grain milling fineness modulus, $\mathrm{mm} ; \mathrm{G}$-grain milling granulation, $\mathrm{mm}$; $\mathrm{F}$ - seed crushing resistance, $\mathrm{kgf} / \mathrm{cm}^{2} ; \mathrm{E}$-seed elastic modulus, $\mathrm{kgf} / \mathrm{cm}^{2} ; \rho$-density of the material to be milled, $\mathrm{kg} / \mathrm{m}^{3}$; 
- the dynamic system rotor-hammers, the concave (grooved surface)

Because not all of the parameters have an equally large influence, determinations have only been made for some of them.

To demonstrate the influence of the concave (grooved surface in the milling chamber) on the cereal grain crushing process, tests were performed on open chamber hammer mill, shown in Figure 6, equipped with concave using the following seeds:

1) Seeds with moisture content:

-maize 13.6\%;

- barley $13.3 \%$;

2) Mill constructive characteristics:

- sieve with $ø 3 \mathrm{~mm}$ holes;

- sieve with $\varnothing 5 \mathrm{~mm}$ holes;

- peripheral speed $77 \mathrm{~m} / \mathrm{s}$;

- angle of coverage $180^{\circ}$ and $255^{\circ}$;

- distance between hammers and sieve $10 \mathrm{~mm}$

Grain milling granulation was determined on the basis of the samples taken: $100 \mathrm{~g}$ grain milling using a sieve battery having the size of the holes: $0.5 ; 1.0 ; 1.6 ; 2.0 ; 2.5$.

Determination of grain milling granulometric composition was achieved by sifting method. This method is most widely used, it is also called the Makarov method quoted by [5] and underlies the determination of the arithmetic average index of particle size. This index is also called the grain milling modulus $M$.

The sifting method consists in passing a defined quantity of particles, in a defined time, on multi stage sieves.

For the correct evaluation of the experiment results, the characteristics of the seeds subjected to the milling operation were determined in the laboratory. The values obtained are shown in Table 1. Experiments were performed for sieves with $180^{\circ}$ and $255^{\circ}$ angle of coverage. The results of the experiments are shown in chart 1 . The tests were carried out with maize and barley seeds.

Table 1. The main characteristics of cereal seeds subject to milling

\begin{tabular}{|l|c|c|c|c|}
\hline \multicolumn{1}{|c|}{ Seed type } & Moisture [\%] & $\begin{array}{c}\text { Hectolitre mass / } \\
{[\mathbf{k g} / \mathbf{h} \mathbf{)}}\end{array}$ & $\begin{array}{c}\text { The weight of 1000 } \\
\text { grains [g] }\end{array}$ & $\begin{array}{c}\text { Impurities } \\
{[\% \mathbf{0}]}\end{array}$ \\
\hline Maize seeds & 13.6 & 70.8 & 284.6 & 0.85 \\
\hline Barley seeds & 13.3 & 56.9 & 38.2 & 13.8 \\
\hline
\end{tabular}

Following the experiments with the above-mentioned equipment, the results presented in the chart in Figure 7 were obtained.

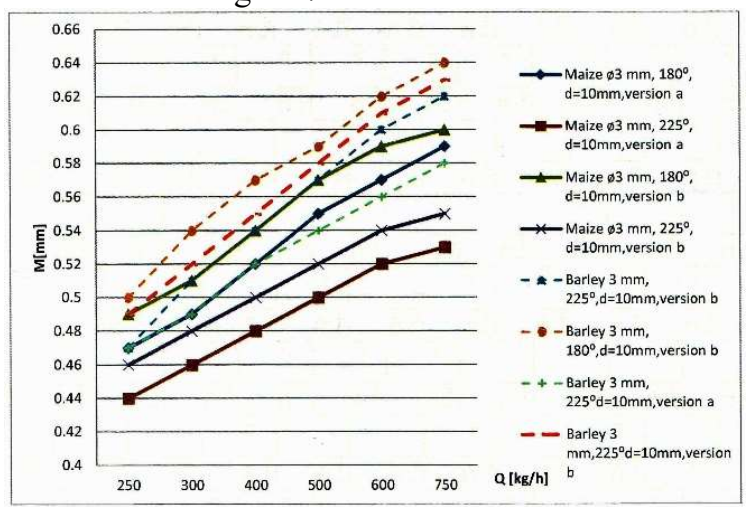

Fig.7. Concaves influence on grain milling modulus $M(\mathrm{~mm})$ in hammer mill grinding process 
Analyzing the chart in Figure 7 it is noticed that:

- the most advantageous mill equipping system is, for maize, a sieve with $255^{\circ}$ angle of coverage with concave, version a, and for barley, the sieve with $255^{\circ}$ angle of coverage, version a.

- modulus $\mathrm{M}$ is better for grinding maize because it has lower crushing resistance than barley seeds.

Following the experiments conducted by various Russian and German researchers it was determined that barley seeds had the greatest resistance to pressing. As a result, it was decided that barley would be the standard for the comparative assessment of the other cereals.

A second series of tests was carried out to determine concaves effect on power consumption, presented in the graph in Figure 8.

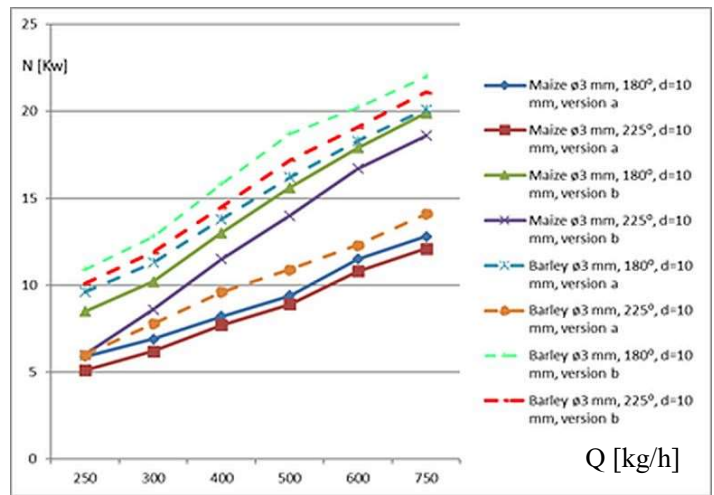

Fig. 8. Concaves influence on the power consumption in hammer mill grinding process

Analyzing the chart in Figure 8 it is noticed that:

- the most advantageous mill equipping system is, for maize, a sieve with $255^{\circ}$ angle of coverage with concave, version a, and for barley, the sieve with $255^{\circ}$ angle of coverage, version a.

\section{Conclusions}

The following conclusions can be drawn from the research carried out and the results obtained:

- seed hardness has a particular influence on the ability to form intermediate products, but also a criterion for estimating energy consumption for shredding.

- knowing that cereal seed fodder represent elastic, plastic and viscous bodies, but in the same time complicated colloidal, capillary-porous bodies where each part of the seed behaves differently, the determination of the resistance force for shredding under different working regimes, allows properly setting the constructive and functional parameters of the hammer mills.

- because of the complexity of the experimental determinations in the milling mechanism theory, the static resistance indicators are used, although they are insufficient to appreciate the dynamic working regime of the machine. In order to assess grains resistance to the milling as a whole, both due to the compressive and shear forces of their anatomical parts, the cereal hardness characteristic is used.

- hardness shows to what extent the seeds break, accidentally or when they are shred. 
- the most advantageous mill equipping system is, for maize, a sieve with $255^{\circ}$ angle of coverage with concave, version a, and for barley, the sieve with $255^{\circ}$ angle of coverage, version a.

- it is recommended to enlarge the working surface of the sieve as this influences the grain milling granulation.

- to increase the milling process intensity in the event of hitting the concave, the particles must rebound in the hammer action area;

- concave's grooves must be constructively chosen so that the particles angle of incidence has the maximum value $\frac{\pi}{2}$;

\section{Acknowledgements}

This paper was financed by grant of the Romanian Research and Innovation Ministry, through Programme 1 - Development of the national research-development system, sub-programme 1.2 Institutional performance - Projects for financing excellence in RDI, contract no. 16PFE.

\section{References}

1. V. Haţieganu,Basics of animal nutrition and veterinary control of feed (Didactic and Pedagogical Publishing House, Bucharest, 1978)

2. A. Păun, Study on concentrated fodder milling process in hammer mills, $\mathrm{PhD}$ thesis(Polytechnic University of Bucharest, 2004)

3. A.Păun,Hammer mills. Study on concentrated fodder milling process, (Terra Nostra, Publishing House, Iasi, 2008)

4. M-V Muntean, O. Marian, O. Ranta, I. Drocas, G. M. Catunescu, The Influence of Hammer Type Used in Grinding Mills on Grist Fineness, Bulletin UASVM Food Science and Technology 70(1), 53-57, (2013)

5. V. Bulgakov, I. Holovach, V. Bandura, S. Ivanovs, A theoretical research of the grain milling technological process for roller mills with two degrees of freedom, INMATEHAgricultural Engineering, 52 no.2, 99-106 (2017),

6. M. Segărceanu, T. Căsăndroiu, Agricultural mechanics studies and research, V, ( 3) ( 1971)

7. A.Păun, R.Ciupercă, B.Ivancu, Gh.Ioniţă, A.Zaica,INMATEH Agricultural Engineering,43, 445-451(2014)

8. Gh.Voicu, L. David, V. Safta, Machine Construction Journal, 4-5, 23-25, (1998)

9. G.Moiceanu, Gh.Voicu, G.Paraschiv, V.Vlăduț,P.Cardei, M. Dincă, Proceedings of the47th International Symposium,Actual Tasks on Agricultural Engineering, 47, 399409 (2019)

10. A. Mikecz,Azallattenyesztesgepei, MezogazdasagiKiado, (Budapesta, 1985) 